\title{
Pancreatic adenocarcinoma: current treatment approaches and controversies
}

\author{
Joseph M. Herman
}

Received: 19 September 2013 / Accepted: 30 September 2013 / Published online: 31 October 2013

(C) Springer-Verlag Berlin Heidelberg 2013

In 2013, there will be an estimated 43,920 new cases and 37, 390 deaths attributed to pancreatic cancer (PCA) in the USA [1]. At diagnosis, a large majority of patients with pancreatic cancer present with unresectable, locally advanced pancreatic cancer (LAPC), or metastatic disease. The prognosis of PCA, regardless of stage, is extremely poor, with a 1-year survival rate of $25 \%$ and a 5 -year survival rate of less than $5 \%$ [2]. Validated early detection tests are unavailable, and screening imaging studies are not recommended. Therefore, patients are often not diagnosed until late in their disease, after their cancer has metastasized to other organs. Despite these horrible statistics, several innovations over the past few years provide hope for earlier detection and improved treatment options for patients with pancreatic cancer. In this issue of the Journal of Radiation Oncology, we will focus on how modern radiation therapy can be optimally integrated with chemotherapy, targeted therapies, and immunotherapy in the treatment of patients with nonmetastatic pancreatic cancer.

Standard options for patients with borderline resectable and unresectable pancreatic cancer include (1) chemotherapy alone, (2) upfront standard chemoradiation (CRT), (3) chemotherapy followed by CRT, or (4) chemotherapy with a short course of stereotactic body radiation therapy (SBRT). Additional research is needed to determine which of these approaches are more likely to be effective for specific patient populations. Major improvements in radiation therapy (RT) such as intensity-modulated radiation therapy (IMRT), image-guided radiation therapy (IGRT), and SBRT now allow for very high doses of conformal radiation to be delivered to the pancreatic tumor resulting in complete pathologic responses in some cases and long-term tumor control in those who remain unresectable [3, 4]. While

J. M. Herman $(\bowtie)$

Department of Radiation Oncology and Molecular Radiation

Sciences, Johns Hopkins University, Baltimore, MD, USA

e-mail: jherma15@jhmi.edu these results are encouraging, a subset of patients remain refractory to RT, likely due to the clinical and genetic diversity of this malignancy. In addition to advances in RT delivery, combination chemotherapy regimens such as 5-FU, irinotecan, and oxaliplatin (FOLFIRINOX) and gemcitabine with abraxane have been shown to improve survival in the metastatic setting and are being introduced in the neoadjuvant, adjuvant, borderline, and locally advanced settings [5]. These improvements in therapy should prolong survival in patients with PCA; however, how these therapies should be optimally administered with radiation therapy for specific patients remains unknown.

Although chemotherapy and radiation reduce the risk of local and distant recurrence, it is unclear why some PCA patients develop widely disseminated disease while others progress only locally or not at all. Known poor prognostic factors available prior to and after surgery include age, comorbid conditions, tumor grade, margin, and nodal status [6]. However, identification of tumor specific biomarker predictors for local and distant recurrence could guide the administration of specific therapies in patients with PCA. A potential prognostic biomarker for PCA is the tumor suppressor gene SMAD4 (DPC4) [7, 8]. SMAD4 encodes a protein, Smad4, that functions as a central mediator of the canonical TGF- $\beta$ signaling pathway that in turn regulates diverse cellular processes including proliferation, differentiation, apoptosis, and migration [9]. Several studies have suggested that immunolabeling for Smad4 protein expression or determining genetic mutation/deletion status of the SMAD4 gene may help to predict overall survival and patterns of failure. To validate these findings, a large intergroup study (RTOG 1201) is including Smad4 status as a pretreatment stratification variable. In the future, identification of additional biomarkers obtained from pretreatment fine-needle and core biopsies from pancreatic tumor specimens and serum will likely determine which patients will benefit from radiation therapy.

This issue of the Journal of Radiation Oncology begins with Kadhim et al., providing an overview of staging and the role 
${ }^{18} \mathrm{~F}$-fluorodeoxyglucose positron emission tomography (PET) in the management of patients with PCA. Drs. Kumar and Jabbour then discuss the definition of borderline resectable PCA and controversies regarding neoadjuvant therapy for resectable PCA. This extensive review is timely, given the recent initiation of the Alliance borderline resectable trial (A021101) which includes FOLFIRINOX, then CRT and surgery (if no local or systemic progression) followed by two cycles of adjuvant gemcitabine. Next, Drs. Trakul, Koong, and Chang review the role of radiation therapy in the adjuvant setting and reflect on how chemotherapy and radiation should be optimally sequenced and/or combined in order to prevent local recurrence and improve survival. Hypfractionated SBRT has been shown to be effective in non-small lung cancer and central nervous system tumors. However, data supporting the role of SBRT in abdominal tumors such as pancreatic cancer are limited by small numbers and heterogeneity in dose and fractionation schedules. In this issue, Hong et al. provide an updated review of the role of SBRT in the neoadjuvant and unresectable settings and provide guidance for optimal integration of SBRT with chemotherapy in patients with PCA. Finally, in this issue, Sharabi et al. provide a concise update of systemic therapies for pancreatic cancer and includes a primer on the role of immunotherapy. They also offer insight as how radiation can be properly sequenced to potentiate the effects of targeted agents and vaccines.

It is truly an exciting time to be involved in the treatment of patients with pancreatic cancer. However, to improve the survival of patients with pancreatic cancer, we must continue to work together to further develop novel therapies and best integrate the sequence and combinations of these therapies to improve outcomes. We must explore novel systemic agents that can potentially enhance the radiosensitizing effects of specific forms of RT while testing radiation protectors that can minimize toxicity. Newer technologies such as IMRT, pencil beam proton therapy, and SBRT appear to result in improved outcomes in selected patients but require further validation. Integration of novel functional imaging (PET) can be used to better stage patients, assist with treatment planning, and assess treatment response. We hope you enjoy this issue as we believe it provides an excellent foundation for oncologists who treat patients with pancreatic cancer and offers a window into the future.

\section{References}

1. Siegel R, Naishadham D, Jemal A (2012) Cancer statistics. CA Cancer J Clin 62(1):10-29

2. Herman JM, Swartz MJ, Hsu CC, Winter J, Pawlik TM, Sugar E, Robinson R, Laheru DA, Jaffee E, Hruban RH, Campbell KA, Wolfgang CL, Asrari F, Donehower R, Hidalgo M, Diaz LA Jr, Yeo C, Cameron JL, Schulick RD, Abrams R (2008) Analysis of fluorouracil-based adjuvant chemotherapy and radiation after pancreaticoduodenectomy for ductal adenocarcinoma of the pancreas: results of a large, prospectively collected database at the Johns Hopkins Hospital. J Clin Oncol 26(21):3503-3510

3. Yovino S, Maidment BW 3rd, Herman JM, Pandya N, Goloubeva O, Wolfgang C, Schulick R, Laheru D, Hanna N, Alexander R, Regine WF (2012) Analysis of local control in patients receiving IMRT for resected pancreatic cancers. Int J Radiat Oncol Biol Phys 83(3):916-920

4. Chang DT, Schellenberg D, Shen J, Kim J, Goodman KA, Fisher GA, Ford JM, Desser T, Quon A, Koong AC (2009) Stereotactic radiotherapy for unresectable adenocarcinoma of the pancreas. Cancer 115(3):665-672

5. Conroy T, Desseigne F, Ychou M, Bouche O, Guimbaud R, Becouarn Y, Adenis A, Raoul JL, Gourgou-Bourgade S, de la Fouchardiere C, Bennouna J, Bachet JB, Khemissa-Akouz F, Pere-Verge D, Delbaldo C, Assenat E, Chauffert B, Michel P, Montoto-Grillot C, Ducreux M (2011) Groupe Tumeurs Digestives of Unicancer. PRODIGE Intergroup. FOLFIRINOX versus gemcitabine for metastatic pancreatic cancer. N Engl J Med 364(19):1817-1825

6. Hsu CC, Wolfgang CL, Laheru DA, Pawlik TM, Swartz MJ, Winter JM, Robinson R, Edil BH, Narang AK, Choti MA, Hruban RH, Cameron JL, Schulick RD, Herman JM (2012) Early mortality risk score: identification of poor outcomes following upfront surgery for resectable pancreatic cancer. J Gastrointest Surg 16(4):753-761

7. Blackford A, Serrano OK, Wolfgang CL, Parmigiani G, Jones S, Zhang X, Parsons DW, Lin JC, Leary RJ, Eshleman JR, Goggins M, Jaffee EM, Iacobuzio-Donahue CA, Maitra A, Cameron JL, Olino K, Schulick R, Winter J, Herman JM, Laheru D, Klein AP, Vogelstein B, Kinzler KW, Velculescu VE, Hruban RH (2009) SMAD4 gene mutations are associated with poor prognosis in pancreatic cancer. Clin Cancer Res 15(14):4674-4679

8. Iacobuzio-Donahue CA, Fu B, Yachida S, Luo M, Abe H, Henderson CM, Vilardell F, Wang Z, Keller JW, Banerjee P, Herman JM, Cameron JL, Yeo CJ, Halushka MK, Eshleman JR, Raben M, Klein AP, Hruban RH, Hidalgo M, Laheru D (2009) DPC4 gene status of the primary carcinoma correlates with patterns of failure in patients with pancreatic cancer. J Clin Oncol 27(11):1806-1813

9. Yachida S, White C, Naito Y, Zhong Y, Brosnan JA, Macgregor-Das AM, Morgan RA, Saunders T, Laheru D, Herman JM, Hruban RH, Klein AP, Jones S, Velculescu VE, Wolfgang C, Iacobuzio-Donahue CA (2012) Clinical significance of the genetic landscape of pancreatic cancer and implications for identification of potential long term survivors. Clin Cancer Res 18(22):6339-6347 